\title{
Systemic Delivery of Dysferlin Overlap Vectors Provides Long-Term Gene Expression and Functional Improvement for Dysferlinopathy
}

\author{
Rachael A. Potter, ${ }^{1, \dagger}$ Danielle A. Griffin, ${ }^{1, \dagger}$ Patricia C. Sondergaard, ${ }^{1}$ Ryan W. Johnson, \\ Eric R. Pozsgai, ${ }^{1,3}$ Kristin N. Heller, Ellyn L. Peterson, ${ }^{1}$ Kimmo K. Lehtimäki, Hillarie P. Windish, \\ Plavi J. Mittal, ${ }^{4}$ Douglas E. Albrecht, Jerry R. Mendell, ${ }^{1,2}$ and Louise R. Rodino-Klapac ${ }^{1-3, *}$ \\ ${ }^{1}$ Center for Gene Therapy, The Research Institute at Nationwide Children's Hospital, Columbus, Ohio; ${ }^{2}$ Department of Pediatrics and Neurology; ${ }^{3}$ Integrated \\ Biomedical Science Graduate Program, College of Medicine; The Ohio State University, Columbus, Ohio; The Ohio State University, Columbus, Ohio; \\ ${ }^{4}$ The Jain Foundation, Seattle, Washington; ${ }^{5}$ Charles River Discovery Services, Kuopio, Finland. \\ ${ }^{\dagger}$ These authors contributed equally to this work.
}

Dysferlinopathies comprise a family of disorders caused by mutations in the dysferlin (DYSF) gene, leading to a progressive dystrophy characterized by chronic muscle fiber loss, fat replacement, and fibrosis. To correct the underlying histopathology and function, expression of full-length DYSF is required. Dual adenoassociated virus vectors have been developed, defined by a region of homology, to serve as a substrate for reconstitution of the full $6.5 \mathrm{~kb}$ dysferlin cDNA. Previous work studied the efficacy of this treatment through intramuscular and regional delivery routes. To maximize clinical efficacy, dysferlin-deficient mice were treated systemically to target all muscles through the vasculature for efficacy and safety studies. Mice were evaluated at multiple time points between 4 and 13 months post treatment for dysferlin expression and functional improvement using magnetic resonance imaging and magnetic resonance spectroscopy and membrane repair. A systemic dose of $6 \times 10^{12}$ vector genomes resulted in widespread gene expression in the muscles. Treated muscles showed a significant decrease in central nucleation, collagen deposition, and improvement of membrane repair to wild-type levels. Treated gluteus muscles were significantly improved compared to placebo-treated muscles and were equivalent to wild type in volume, intra- and extramyocellular lipid accumulation, and fat percentage using magnetic resonance imaging and magnetic resonance spectroscopy. Dual-vector treatment allows for production of full-length functional dysferlin with no toxicity. This confirms previous safety data and validates translation of systemic gene delivery for dysferlinopathy patients.

Keywords: AAV, gene therapy, dysferlin, systemic delivery, LGMD2B

\section{INTRODUCTION}

THERE IS NO CURE OR TREATMENT for dysferlinopathies, a group of related disorders with varying clinical manifestations caused by absent or mutant dysferlin $(D Y S F)$. Typically, patients present in their late teens or early twenties with slowly progressive muscle weakness and high serum creatine kinase (CK). ${ }^{1}$ Approximately one-third of patients become wheelchair dependent within 15 years of onset. There are two major clinical presentations of dysferlin deficiency. Limb girdle muscular dystro- phy type $2 \mathrm{~B}$ is one of the most common limb girdle muscular dystrophies in the United States, with worldwide reports of incidence of $1 / 100,000-1 /$ $200,000,{ }^{2}$ while Miyoshi myopathy is a more limited distal lower extremity form of dysferlinopathy. Miyoshi myopathy often begins distally with atrophy of the gastrocnemius muscle and then spreads over time to affect proximal muscles. ${ }^{3}$ Regardless of where muscle weakness begins, the disease progresses to the majority of muscles in the trunk, all limb muscles, the diaphragm, and, in some cases,

${ }^{*}$ Correspondence: Dr. Louise R. Rodino-Klapac, Center for Gene Therapy, The Research Institute at Nationwide Children's Hospital, Room 3016, 700 Childrens Drive, Columbus, OH 43205. E-mail: Louise.Rodino-Klapac@nationwidechildrens.org

(c) Rachael A. Potter et al. 2017; Published by Mary Ann Liebert, Inc. This is an Open Access article distributed under the terms of the Creative Commons Attribution License, which permits unrestricted use, distribution, and reproduction in any medium, provided the original work is properly cited. 
the heart. ${ }^{4}$ Therefore, treatment that targets all muscles is imperative. In most cases, pathogenic $D Y S F$ mutations lead to absence of dysferlin protein expression, causing a progressive muscular dystrophy, with chronic muscle fiber loss, inflammation, fat replacement, and fibrosis, all of which are thought to contribute to deteriorating muscle weakness. $^{5}$

DYSF is a large gene spanning 55 exons over $150 \mathrm{~kb}$ of genomic DNA. ${ }^{6}$ The associated $6.2 \mathrm{~kb}$ cDNA codes the dysferlin protein, which is composed of multiple $\mathrm{N}$-terminal $\mathrm{C} 2$ domains with a transmembrane C-terminal region. ${ }^{6-8}$ Dysferlin has been implicated in multiple roles within skeletal muscle, including sarcolemmal membrane repair, ${ }^{1,9-11}$ T-tubule structure and function, ${ }^{12}$ vesicle trafficking, ${ }^{13}$ and endocytosis. ${ }^{14}$ Although the expression of dysferlin in monocytes may contribute to disease severity, ${ }^{15-17}$ pathogenesis has been shown to be intrinsically linked to skeletal muscle. ${ }^{18,19}$ Moreover, anti-inflammatory glucocorticoids are ineffective in treating the disease ${ }^{20}$ in spite of being the standard of care for Duchenne muscular dystrophy and in spite of the characterized inflammation in dysferlinopathy muscle biopsies. ${ }^{21,22}$ The most widely studied DYSF function is membrane repair and is the target of many therapeutics. $^{23,24}$ Collectively, preclinical studies that have assessed gene replacement or surrogate gene replacement have shown that multiple strategies exhibit some efficacy in restoring membrane repair, ${ }^{19,25}$ but only those that have delivered full-length dysferlin have been able to correct the underlying histopathologic ${ }^{9,26}$ and T-tubule formation $^{27}$ defects. Thus, there is strong rationale to develop therapies that deliver the entire $D Y S F$ transcript.

Gene transfer as a treatment strategy has undergone profound development in recent years and is particularly applicable for recessive disorders. ${ }^{9,11,28-31}$ Moreover, the advancement of vector production yield capabilities ${ }^{32-34}$ and systemic treatment approaches has revolutionized the opportunities to create truly clinically meaningful therapies. ${ }^{35}$ Adeno-associated virus (AAV) is a nonpathogenic vector with serotype-dependent tropism for muscle. Serotypes 1, 5, 6, 8, 9, and rh74 have all been shown to transduce muscle efficiently. ${ }^{11,36,37}$ It has been demonstrated that AAVrh74 broadly distributes DYSF to skeletal muscle following vascular delivery. ${ }^{11,38} \mathrm{~A}$ major limitation of all AAV vector serotypes is their restrictive packaging capacity of $\sim 5 \mathrm{~kb}$, which prevents the encapsidation of large genes. ${ }^{39}$ Multiple strategies have emerged in the field to address this constraint, including miniaturization of transgenes, concatemerization splicing, and dual vector delivery. ${ }^{11,27,32,40,41}$ Previous work with a dual vector delivery strategy utilized homologous recombination of a split transgene, which allowed for production of full-length protein. ${ }^{11}$

Current treatment strategies are limited, emphasizing the need for an effective therapeutic approach. Early intervention and systemic delivery of DYSF offers significant advantages, including gene restoration to all muscles prior to limitations introduced by fat and fibrosis, and reducing the immune response following multiple intramuscular injections. ${ }^{42,43}$ This study presents delivery of dual vectors carrying the DYSF cDNA systemically in a dysferlin-deficient mouse model. This has resulted in long-term widespread expression in skeletal and cardiac muscle with improvement in outcome measures, including reduced fibrosis and central nucleation, membrane repair capability, and multiple magnetic resonance imaging (MRI)-based measurements, including reversal of intramuscular lipids and fat percentage. Additionally, systemic delivery in a nonhuman primate (NHP) model confirmed previous indications of vector safety in large animals.

\section{MATERIALS AND METHODS \\ Dysferlin gene construction}

For all gene transfer studies, human dysferlin cDNA (Genbank \#NM_003494.3) was used. The dual vector dysferlin cassettes were generated to encompass the $5^{\prime}$ or the $3^{\prime}$ portion of the full-length dysferlin cassette, as previously described. ${ }^{9,11}$ The $5^{\prime}$ cassette contains the MHCK7 promoter, the chimeric intron, and the first $3370 \mathrm{bp}$ of the dysferlin cDNA flanked by AAV2 inverted terminal repeats. The $3^{\prime}$ cassette contains the remaining $3866 \mathrm{bp}$ of the dysferlin cDNA and the native $3^{\prime}$ untranslated region/polyA sequence. The dual vectors result in a $1 \mathrm{~kb}$ overlap region that serves as a substrate for recombination to generate the fulllength dysferlin cDNA. Both constructs were fully sequenced to confirm plasmid fidelity.

\section{AAV vector production}

pAAV.MHCK7.DYSF5'.PTG and pAAV.DYSF3' .PolyA were packaged into AAV serotype rh74 capsid using the standard triple transfection protocol, as previously described. ${ }^{11}$ A quantitative polymerase chain reaction (PCR)-based titration method was used to determine an encapsulated vg titer utilizing a Prism 7500 Fast Taqman detector system (PE Applied Biosystems). ${ }^{44}$ The follow- 
ing primers/probes were used: AAVrh74.MHCK7 .DYSF5'.PTG: F primer CCAACACCTGCTGCC TCTAAA, R primer GTCCCCCACAGCCTTGTTC, Probe TGGATCCCCTGCATGCGAAGATC; AAVrh74 .DYSF3'.PolyA: F primer AGATCACCCCACTTC CATCATT, $\mathrm{R}$ primer TGAAATATGTCTGAGCT GATCCAAA, Probe CCTTCTCCCCCAACCCAAC GCT.

\section{Animal models}

Dysferlin-deficient mouse strain. Stocks of C57BL/6, 129-Dysf ${ }^{\text {tm1Kcam } / J \text {, and B6.A-Dysf }}{ }^{\text {prmd/ }}$ GeneJ BlaJ mice were bred and maintained as homozygous animals in standardized conditions in the Animal Resources Core at The Research Institute at Nationwide Children's Hospital. BlaJ mice were maintained in a private colony at the Jackson Laboratories sponsored by the Jain Foundation. The BlaJ mice used for the MRI/ magnetic resonance spectroscopy (MRS) analysis were maintained at PsychoGenics, Tarrytown, NY. BLaJ strain mice were previously backcrossed 10 times onto C57BL/6J mice. Control mice (C57BL/6) were littermates to control for any behavioral variability. In order to undergo MRI/MRS, the mice were transferred at 6 months of age to Charles River Laboratories, Finland (study number 112314). Mice were maintained on a Teklad Global Rodent Diet (3.8\% fiber, $18.8 \%$ protein, $5 \%$ fat chow) with a 12:12 h dark:light cycle. Procedures used in experiments were approved by the Institutional Animal Care and Use Committee at Nationwide Children's Hospital (protocol AR08-00017).

NHP. Vendors provided serum from rhesus macaques before animal purchase for determination of AAVrh74 binding antibody titers. Seronegative animals (categorized by $<1: 50$ total antibody titer dilution via enzyme-linked immunosorbent assay [ELISA]) were obtained and housed in twos or threes to promote socialization in the Animal Resources Core at the Research Institute at Nationwide Children's Hospital. All procedures were approved by the Institutional Animal Care and Use Committee at Nationwide Children's Hospital (protocol AR06-00116).

\section{In vivo gene delivery}

In both primate and mouse studies, vector was delivered in a 1:1 ratio systemically via the vasculature. BlaJ mice were injected in the tail vein at one of two time points- 8 weeks or 6 months-with $6 \times 10^{12} \mathrm{vg}$ (total dose $3 \times 10^{12} \mathrm{vg}$ of each vector). The 8-week old cohort was necropsied at 28 weeks of age for histologic and expression analysis. A separate cohort of mice, also injected at 8 weeks of age, was necropsied at 15 months of age following the final MRI scans. CK levels were determined from serum samples collected at each time point for all mice in the study. The BlaJ mice injected at 6 months of age were necropsied 3 months post injection. Tibialis anterior muscles from 4 - to 6 -weekold 129-Dysf ${ }^{t m 1 K c a m} / J$ mice were injected with $2 \times 10^{11} \mathrm{vg}$ total of AAVrh74.MHCK7.Dysferlin.DV. A $4 \mathrm{~kg}$ rhesus macaque was perfused with $2 \times 10^{14} \mathrm{vg}$ total dose $\left(1 \times 10^{14} \mathrm{vg}\right.$ of each vector $)$ in $50 \mathrm{~mL}$ total volume at a rate of $300 \mathrm{~mL} / \mathrm{h}$ in the cephalic vein.

\section{MRI and MRS}

The following treatment groups were used: group 1-eight wild-type (WT) males treated with saline; group 2-eight BlaJ males treated with saline; and group 3-eight BlaJ males treated with AAVrh74-dysferlin. All study mice from each group were subjected to $11.7 \mathrm{~T}$ (Bruker BioSpec) MRI and $1 \mathrm{H}-\mathrm{MRS}$ at the age of $7,9,12$, and 15 months to assess longitudinal changes in muscle volumes (3D GRE with water excitation/fat suppression, TE/ $\mathrm{TR}=2.7 / 25 \mathrm{~ms}$ at a resolution of $81 \times 94 \times 375 \mu \mathrm{m}^{3}$ ), fat accumulation (same sequence but with water suppression/fat excitation), and gluteal spectroscopic changes (PRESS, TE/TR $=10 / 2,000 \mathrm{~ms}$ ). At 15 months of age, all mice were evaluated by MRI, but MRS was only performed on control and BlaJAAV mice due to excessive fat infiltration in BlaJVEH mice, which prevented collection of reliable MRS data. Peak areas for major metabolites (creatine, choline, taurine, and components for intraand extramyocellular lipids) were analyzed using the LC Model (Stephen Provencher, Inc.), and results are given relative to water content in tissue.

\section{Histologic analysis}

All muscles and organs, unless used for membrane repair assays, were embedded in $7 \%$ gum tragacanth and flash frozen in liquid nitrogen cooled in isopentane. Frozen sections $(12 \mu \mathrm{m})$ were collected for immunohistochemistry, immunofluorescence, and Western blot analysis.

\section{Picrosirius red stain and collagen quantification}

Frozen sections placed onto Fisherbrand $\mathrm{Su}$ perfrost charged microscope slides were fixed in $10 \%$ neutral-buffered formalin for $5 \mathrm{~min}$ and rinsed in distilled water. Slides were then incubated in Solution B (Direct Red 80/2 4 6-Trinitrophenol) from the Picrosirius Red Stain Kit (Polysciences, Inc.; catalog \#24901) for $15 \mathrm{~min}$. After a thorough 
rinse in distilled water, the slides were placed in Solution C $(0.1 \mathrm{~N}$ hydrochloride acid) for $2 \mathrm{~min}$. Slides were counterstained for 3 min with $1 \%$ fast green in $1 \%$ glacial acetic acid from Poly Scientific (catalog \#S2114) using a 1:10 dilution in deionized water. Finally, the slides were rinsed again in distilled water, dehydrated in graded ethanol, cleared in xylene, and mounted with coverslips using Cytoseal 60 media from Thermo Fisher Scientific (catalog \#8310). Images were taken using the AxioVision 4.9.1 software. For analysis of Sirius red staining and percent collagen quantification, the contrast between the red and green colors was enhanced using Adobe Photoshop. The color deconvolution plugin in the ImageJ software program was selected, and the RGB color deconvolution option was used. The red image includes all connective tissue from the Sirius red stain. The green image includes all muscle from the fast green counterstain. Only the red image and the original image were used. A threshold was then applied to the images to obtain black and white images, with areas positive for collagen in black and negative areas in white. Using the measure function, the area of collagen was calculated. The total tissue area was then determined by converting the originally image to "8-bit" and adjusting the threshold to 254, which will be one unit below completely saturating the image. The total tissue area was then measured, as done previously, and total area was recorded. The percentage of collagen was calculated by dividing the area of collagen by the total tissue area. The mean percentage for each individual was then calculated.

\section{Immunohistochemistry}

Immunofluorescence staining for dysferlin was performed on all transduced tissue to assess efficacy of gene transfer. For dysferlin detection, tissue sections $(12 \mu \mathrm{m})$ were incubated with rabbit anti-human dysferlin monoclonal antibody (Abcam) at 1:100 in blocking solution (10\% goat serum, $0.1 \%$ Tween-20 in tris-buffered saline [TBS]) for $1 \mathrm{~h}$ at $25^{\circ} \mathrm{C}$ in a wet chamber. Sections were washed with TBS $3 \times 20 \mathrm{~min}$, re-blocked, and then incubated for $45 \mathrm{~min}$ at $25^{\circ} \mathrm{C}$ with an Alexa 568 goat anti-rabbit antibody (Invitrogen) at a 1:250 dilution. Sections were washed in phosphate-buffered saline (PBS) for $3 \times 20 \mathrm{~min}$ and mounted with Vectashield mounting medium (Vector Laboratories). Images were captured with a Zeiss Axioskop2 Plus Microscope and Axiocam MRC5 camera. Four random $20 \times$ images (each field with an average of 150 muscle fibers) were captured per muscle, and the number of fibers with dysferlin labeling was counted and expressed as the percent of total number of fibers.

Immunohistochemical staining for CD8a was performed with rat anti-CD8a antibody (Thermo Fisher Scientific) and an anti-rat Ig horseradish peroxidase (HRP) detection kit (BD Biosciences), following the manufacturer's directions. Images were captured with a Zeiss Axioskop2 Plus microscope and Axiocam MRC5 camera. Four random $20 \times$ images (each field with an average of 150 muscle fibers) were captured per muscle, and the number of CD8a-positive cells was counted and expressed as number of positive cells per square area. Unpaired $t$-test statistical analysis was performed to compare treatment effect on cells $/ \mathrm{mm}^{2}$.

\section{Morphometrics}

Centralized nuclei counts were performed on sections of muscle stained with hematoxylin and eosin (H\&E) from treated animals. Four random $20 \times$ fields of $12 \mu \mathrm{m}$ sections for each muscle were captured, and the number of fibers with central nuclei was counted and expressed as a percentage of the total number of fibers. Two-way analysis of variance (ANOVA) was performed to compare treatment effect on central nucleation.

\section{Western blot analysis}

From each muscle, fresh-frozen serial tissue sections were taken for protein preparation. Muscle samples harvested from treated and control groups were compared to WT tissue for levels of vector-mediated dysferlin compared to endogenous dysferlin. Protein $(5 \mu \mathrm{g}$ for WT lanes and $10 \mu \mathrm{g}$ for all other lanes) extracted from treated and control samples was separated by SDS-PAGE (3-8\% Novex NuPAGE gradient gels; Invitrogen), blotted on polyvinylidene fluoride membrane, and probed with NCL-Hamlet (Novocastra) primary antibody (for dysferlin) at a dilution of 1:1,000, or $\gamma$-tubulin antibody (Sigma-Aldrich) at a dilution of 1:10,000, followed by HRP-labeled goat anti-mouse IgG (1:5,000; Millipore) or goat anti-rabbit IgG (1:5,000; Millipore), and signal captured on Hyblot CL autoradiography film (Denville). Densitometry analysis was performed using ImageQuant TL.

\section{Membrane repair analysis}

Six-month-old BlaJ mice were injected with $6 \times 10^{12} \mathrm{vg}$ of AAVrh74.MHCK7.Dysferlin.DV into the tail vein. Muscles were harvested 12 weeks post injection and subjected to a laser-induced injury. Membrane repair assay was performed on the left and right flexor digitorum brevis (FDB) muscles of BlaJ-AAV-treated $(n=6)$, BlaJ saline-treated $(n=5)$, 
and age-matched C57BL6 $(n=5)$ mice, as previously described, when the mice were 9 months old. ${ }^{11}$ Briefly, FDB fibers were isolated using a solution containing $2 \% \mathrm{w} / \mathrm{v}$ collagenase type I suspended in Dulbecco's modified Eagle's medium. Following dissociation of the muscle, fibers were placed in a glass-bottom dish holding $2.5 \mu \mathrm{M}$ of FM1-43 dye in Dulbecco's PBS (no $\mathrm{Ca} / \mathrm{Mg}$ ) supplemented with $1.5 \mathrm{mM}$ of $\mathrm{Ca}^{2+}$. Fibers were subjected to laser injury using a FluoView ${ }^{\circledR}$ FV1000 two-photon confocal laser-scanning microscope (Olympus). Fibers were damaged with an $850 \mathrm{~nm}$ laser-guided spot of $4.48 \mu \mathrm{m}$ at $20 \%$ power and imaged every $5 \mathrm{~s}$ for $190 \mathrm{~s}$ to visualize FM1-43 dye uptake. On average, 7-10 fibers were imaged per muscle per mouse (total $60 \mathrm{WT}, 48$ BlaJ-, and 69 BlaJ-AAV-treated fibers). Fluorescence intensity of dye infiltration surrounding the damage site on the membrane was analyzed with Image $\mathrm{J}$ software by measuring the integrated density of the pixel intensity within the defined area. To do so, under a $2 \times$ zoom setting on ImageJ, a region of interest (ROI) rectangular box measuring $7.5 \mu \mathrm{m} \times 10 \mu \mathrm{m}$ is drawn and used to measure the intensity of dye in that region. In the analysis, measured fluorescence intensity at an individual time point was normalized to initial intensity measured at $t=-5 \mathrm{~s}$ (preinjury) using the equation $N I=\left(I-I_{0}\right) / I_{0}$, where $N I$ is the normalized intensity, $I$ is the measured intensity, and $I_{0}$ is the intensity at $t=-5 \mathrm{~s}$. When fluorescence intensity was analyzed, values from all fibers from each strain were averaged together. A two-way ANOVA was performed to determine statistical significance between treated and untreated fibers at each time point $(p<0.001)$. BlaJ, WT fibers, and AAVrh74.DYSF.DV-treated BlaJ fibers were significantly different at 190 s post injury.

\section{Immunologic assays}

For the NHP, whole blood samples were collected biweekly and used for ELISA and enzymelinked immunosorbent spot assay (ELISpot) to track immunologic response to the viral capsid, AAVrh74, and the dysferlin transgene product. ELISAs were performed in 96-well Nunc Maxisorb ELISA plates coated with $2 \times 10^{9}$ vg AAVrh74 per well in carbonate buffer. Serum samples were diluted from 1:5 through 1:819,200 in blocking solution (5\% nonfat dry milk, $1 \%$ normal goat serum [Invitrogen] in $\mathrm{PBS}^{-/}$) and added to wells for $1 \mathrm{~h}$ at room temperature. Sera from previously screened positive and negative NHPs were used for controls. Goat anti-monkey IgG-HRP (Sigma-Aldrich) was used as the secondary antibody for $30 \mathrm{~min}$ at room temperature followed by exposure with
Ultra TMB-ELISA solution (Thermo Fisher Scientific). Absorbance of wells at OD450 was measured and used to calculate titer of positive reaction.

Peripheral blood mononuclear cells (PBMCs) were separated from whole blood samples through density gradient centrifugation, as previously described. ${ }^{45}$ Briefly, fresh blood samples were spun in a tabletop centrifuge (Sorval Legend RT), and the top plasma layer was removed and stored at $-80^{\circ} \mathrm{C}$. The remaining blood was mixed with $\mathrm{PBS}^{-/-}$(Invitrogen), underlayed with Ficoll-Paque (Thermo Fisher Scientific), and spun for density gradient separation. The middle layer containing the PBMCs was removed and subjected to various wash/spin cycles before a final resuspension in CellGro RPMI1640 media (Thermo Fisher Scientific) supplemented with $10 \%$ fetal calf serum (Thermo Fisher Scientific), penicillin, and streptomycin. PBMCs were then plated in IP filter plates (Millipore) at a density of $2 \times 10^{5}$ cells/well. IP plate wells were pre-coated with monoclonal antibody provided in monkey interferon- $\gamma$ ELISpot kit (U-Cytech Biosciences). Three peptide pools were used for the AAVrh74 capsid protein (Genemed Synthesis) containing 34-36 peptides, each 18 amino acids long and overlapping by 11 residues. Ten peptide pools encompassing the dysferlin protein (Genemed Synthesis) containing 48 peptides, each 15 amino acids long and overlapping by 10 residues. Concanavalin A (Sigma-Aldrich; $1 \mu \mathrm{g} /$ $\mathrm{mL}$ ) served as a positive control and $0.25 \%$ dimethylsulfoxide as a negative control. Peptides were added directly to the wells at a final concentration of $1 \mu \mathrm{g} / \mathrm{mL}$. After the addition of PBMCs and peptides, the plate was incubated at $37^{\circ} \mathrm{C}$ in 5$7 \% \mathrm{CO}_{2}$ and $100 \%$ humidity for $36-48 \mathrm{~h}$. Following incubation, the plate was developed according to the manufacturer's protocol. Interferon- $\gamma$ spot formation was counted using Immunospot software (Series 3B Analyzer; Cellular Technology Ltd.).

Blood samples from the NHPs were analyzed monthly for chemistry panel and complete blood count (CBC) testing internally.

\section{AAVrh74.DYSF.DV biodistribution analysis}

Quantitative PCR was performed to quantify the number of vector genome copies present in targeted muscle as well as non-targeted organs according to standard methods. ${ }^{39}$ Briefly, DNA was isolated from frozen tissue (twenty $20 \mu \mathrm{m}$ sections) according to DNEasy purification kit protocol (Qiagen). Absolute quantification for the $5^{\prime}$ and $3^{\prime}$ vectors were established by creation of standard amplification curves using HindIII-linearized pAAVrh74 
.MHCK7.DYSF5'.PTG and NotI-linearized pAAV .DYSF3'.POLYA, respectively. Standards ranged from $10^{6}$ to $10^{1}$ copies per reaction. All sample reactions contained $100 \mathrm{ng}$ of DNA, and resulting copy numbers were determined according to standard curves performed in parallel. Copy numbers were reported per microgram of genomic DNA.

Each vector DNA sequence was quantified via the Taqman system (Applied Biosystems) using vector-specific primer/probe sets. For AAVrh74 .MHCK7.DYSF5'.PTG, the following sequences were used: forward primer, 5'- CCAACACCTGC TGCCTCTAAA-3'; reverse primer, 5'- GTCCCCC ACAGCCTTGTTC-3'; probe, 5'-TGGATCCCCTGC ATGCGATC-3' with 5' 6-FAM fluorophore, internal $\mathrm{ZEN}^{\circledR}$ quencher, and $3^{\prime}$ Iowa Black ${ }^{\circledR} \mathrm{FQ}$ quencher (IDT). For AAV.DYSF3'.POLYA, the following sequences were used: forward primer, 5'-AGATCA CCCCACTTCCATCATT-3'; reverse primer, 5'-TG AAATATGTCTGAGCTGATCCAAA-3'; probe, 5'-C CTTCTCCCCCAACCCAACGCT-3' with 5' 6-FAM fluorophore, internal ZEN ${ }^{\circledR}$ quencher, and 3' Iowa Black ${ }^{\circledR} \mathrm{FQ}$ quencher.

\section{Statistical analysis}

Data were expressed as the mean \pm standard error of the mean (error bars) and analyzed using a one-way ANOVA or two-way ANOVA with multiple comparisons between groups and statistical significance determined through Tukey's post hoc analysis test using GraphPad Prism 5 (GraphPad Software) unless otherwise specified. Asterisks in figures and reported data denote level of statistical significance as follows: ns, no significance; $* p<0.05$; * $p<0.01 ; * * * p<0.001$; and ${ }^{* * * *} p<0.0001$.

\section{RESULTS}

Previous work ${ }^{11}$ showed successful gene transfer in dysferlin-null mice through multiple delivery routes, including intramuscular, isolated vascular, and systemic injections. As a continuation of that work, a detailed time course was performed, fol-
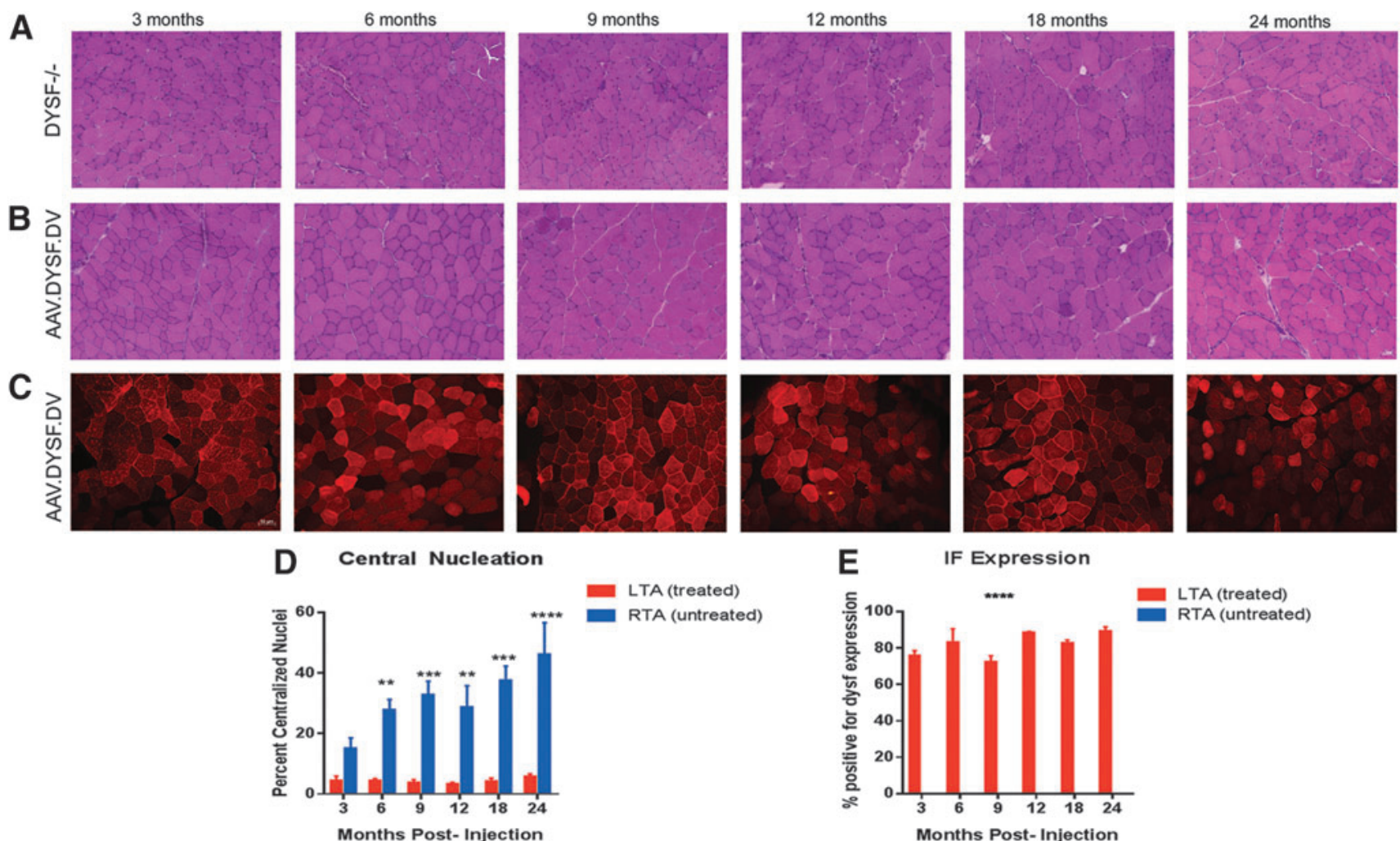

Figure 1. Sustained long-term expression following intramuscular delivery in dysferlin null mice. Four-week-old $D y s f^{\prime-}$ mice were injected with $2 \times 10^{11}$ vg total dose of AAVrh74.MHCK7.DYSF.DV into the left tibialis anterior (TA) muscle and followed for 3-24 months to monitor expression and histology ( $n=3$ per time point). (A) Hematoxylin and eosin (H\&E) staining demonstrates a significant reduction in centrally located nuclei in the treated TA compared to (B) contralateral control TA muscles injected with saline. (C) Anti-dysferlin immunofluorescence staining demonstrates dysferlin transgene expression was sustained throughout all time points (3-24 months). (D) At 6, 9, 12, 18, and 24 months post delivery, there was a significant decrease in central nucleation to <5\%. Excluding the 3 month time point, all values were significant $(p \leq 0.01)$ for central nucleation quantification. (E) There was no significant decrease in the percentage of dysferlin-positive fivers over time, and contralateral (right side) muscles demonstrated no dysferlin expression. Two-way analyses of variance (ANOVAs) were utilized to identify differences in the means between treated and untreated cohorts. Error bars are represented as mean \pm standard error of the mean (SEM; $p<0.05)$. 
lowing intramuscular delivery over 24 months. Figure 1 demonstrates that disease progression is significantly halted up to 24 months in 129$D y s f^{t m 1 K c a m} / J$ mice injected intramuscularly with AAVrh74.DYSF.DV at a young age (4 weeks). Treated muscles show a reduction in centralized nuclei to $<5 \%$ post gene delivery (Fig. 1 and Supplementary Fig. S1) and high levels of sustained dysferlin expression $>70 \%$ through all time points ( $n=3$ per group; Fig. 1). Strong cytoplasmic dysferlin staining post gene transfer has been previously noted. ${ }^{9,11,25,26}$ Dysferlin is expressed at both the sarcolemma and intracellular membranes, particularly the T-tubules. ${ }^{46}$ In addition to sarcolemmal expression, strong cytoplasmic expression of dysferlin is commonly noted in regenerating fibers in dystrophic patient biopsies ${ }^{3,47}$ as well as following gene delivery.

\section{AAVrh74.DYSF.DV systemic gene transfer in young mice}

The following work presents an intensive study of systemic (intravenous) delivery of AAVrh74 .DYSF.DV with a focus on highly affected muscles in the BlaJ (dysferlin-deficient) mouse model: the psoas and the gluteus muscles. A decision was made to study the BlaJ mouse model, as its phenotype more accurately recapitulates human disease compared to the 129-Dysf model. In a longitudinal study of disease progression and functional deficiencies of the BlaJ model, it has been corroborated that progressive volume loss and fatty infiltration in the gluteal and psoas muscles is the most uniform parameter and identifies consistent disease parameters to human dysferlinopathies. ${ }^{48}$ In BlaJ mice, the psoas muscle shows early signs of dystrophic changes, including high

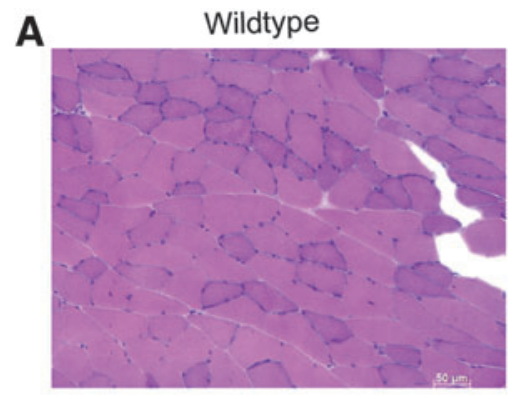

$\mathbf{B}$

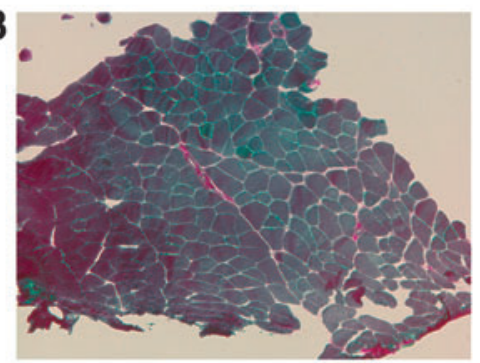

C

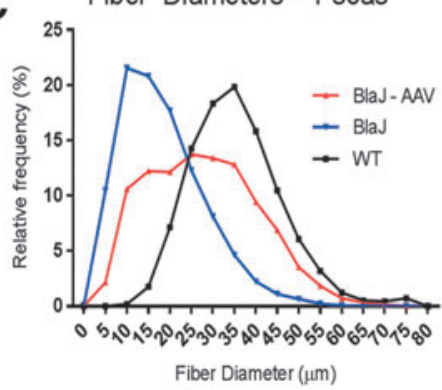

BlaJ - AAV
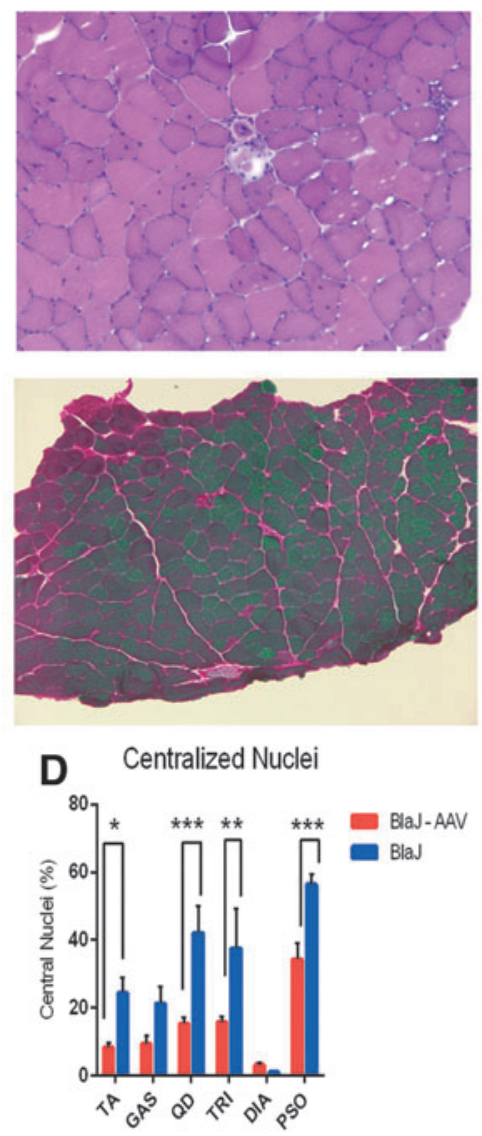

BlaJ
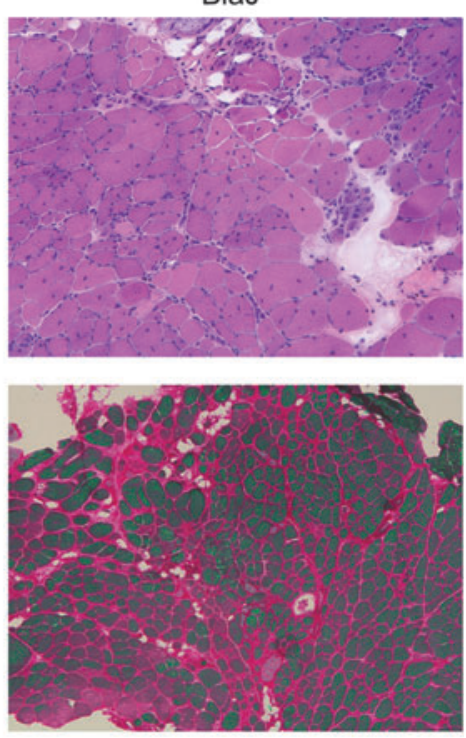

E

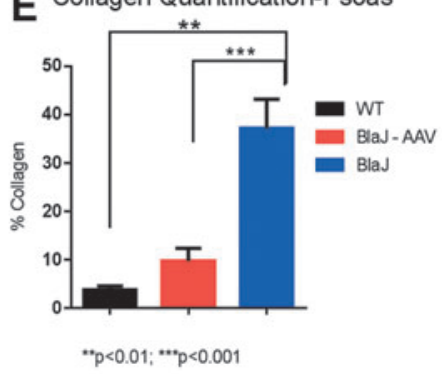

Figure 2. Intravenous delivery of AAVrh74.MHCK7.DYSF.DV improves histological parameters in BlaJ mice. (A) H\&E staining of the psoas muscle 28 weeks post treatment demonstrated improvement in fiber size distribution and reduced central nuclei following intravenous delivery of $6 \times 10^{12} \mathrm{vg}$ total dose of AAVrh74.MHCK7.DYSF.DV in treated BlaJ mice versus saline-treated mice. (B) Picosirius red staining for collagen demonstrated reduction in fibrosis in AAVrh74.MHCK7.DYSF.DV-treated psoas muscles. (C) Following AAVrh74.MHCK7.DYSF.DV delivery, there was a trend toward normal fiber diameters, with a significant increase in mean fiber diameter in treated muscle $(27.8 \pm 0.17 \mu \mathrm{m})$ versus control $(18.4 \pm 0.099 \mu \mathrm{m})$, and reduced central nucleation in the TA, quadriceps, triceps, and psoas muscles. (E) Additionally, there was a significant decrease from $37.0 \%$ to $9.7 \%$ collagen deposition in treated mice compared to saline-treated mice. Two-way ANOVAs were utilized with post hoc analysis to locate differences in central nucleation and fiber diameters. Error bars are represented as mean \pm SEM $(p<0.05)$. 
levels of centralized nuclei, interstitial collagen deposition, and infiltration of inflammatory cells (Fig. 2A). Following intravenous delivery of $6 \times 10^{12}$ vg of AAVrh74.DYSF.DV via the tail vein in 8week-old BlaJ mice $(n=8)$, the psoas muscle was analyzed through multiple measures at 7 months of age (following 28 weeks of treatment), and widespread gene expression was demonstrated throughout all skeletal muscles, with $30.9 \pm 5.0 \%$ of fibers transduced in the psoas muscle. Figure 2 demonstrates that delivery of dysferlin transgene stabilizes the muscle environment, leading to a normalization of fiber size distribution (Fig. 2C), where the mean fiber diameter in treated psoas muscles increased from $27.8 \mu \mathrm{m}$ versus $18.4 \mu \mathrm{m}$ in saline-treated muscle. Significant reductions in centralized nuclei in the treated tibialis anterior, quadriceps, triceps, and psoas muscles were also identified (Fig. 2D and Supplementary Fig. S1). In addition, a significant reduction of CD8 cells in treated muscles $\left(25.59\right.$ cells $\left./ \mathrm{mm}^{2}\right)$ compared to untreated $\left(62.23\right.$ cells $\left./ \mathrm{mm}^{2}\right)$ was demonstrated. Finally, there was a significant reduction in collagen deposition in treated psoas muscles $(9.7 \%)$ compared to untreated BlaJ psoas muscles (37.0\%; Fig. 2E).
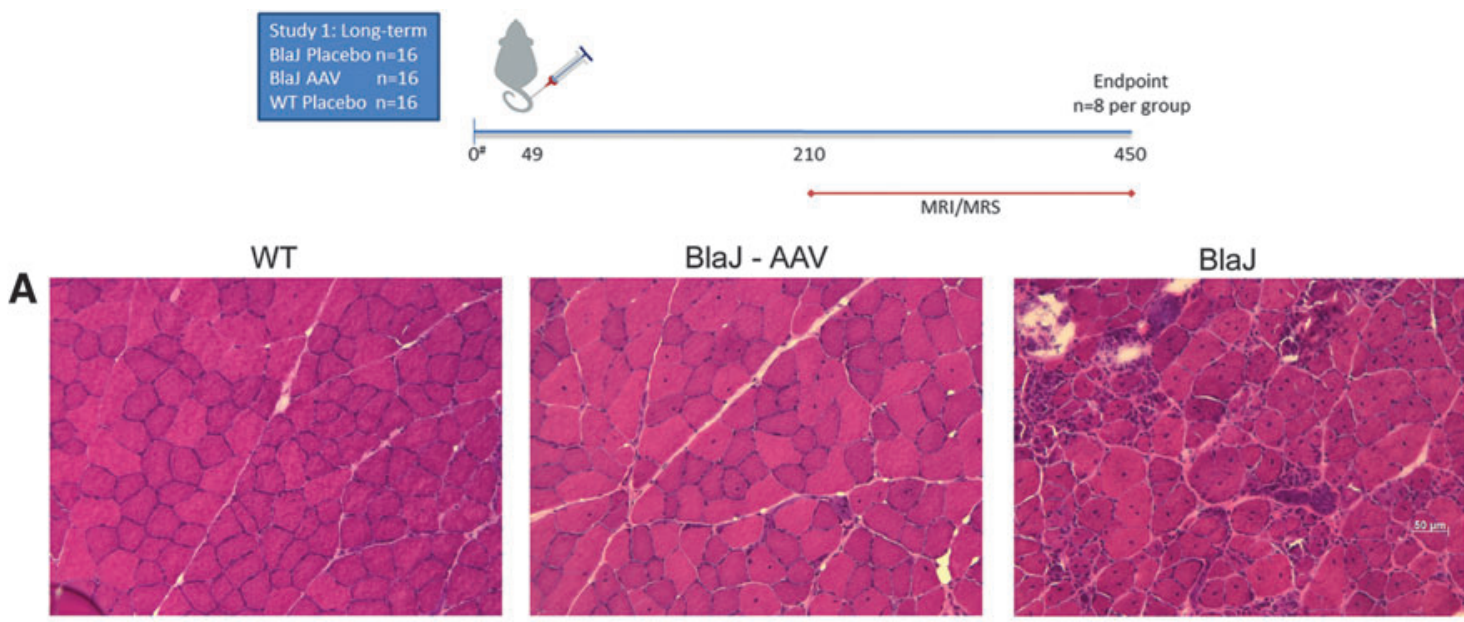

B
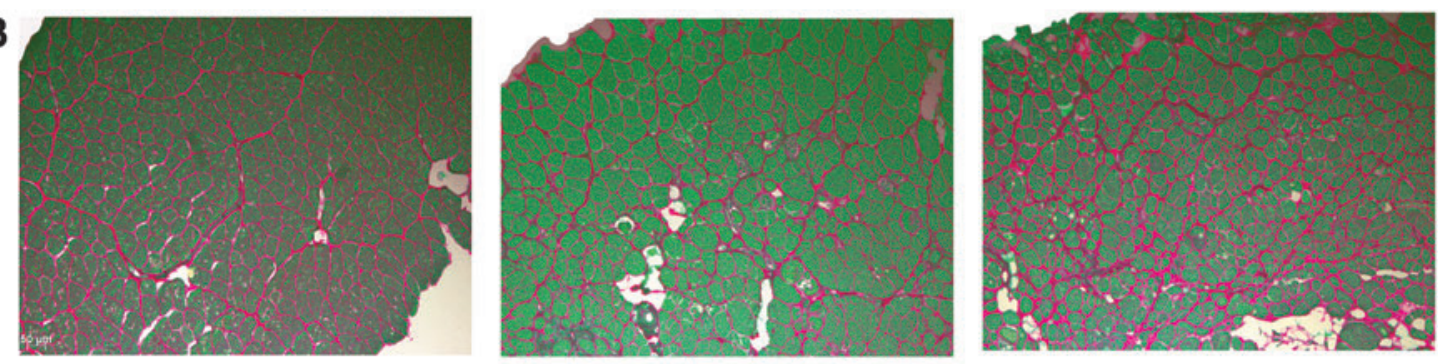

C Fiber Diameters - Gluteus

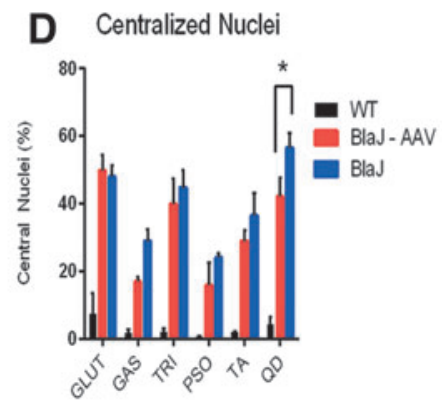

E Collagen Quantification
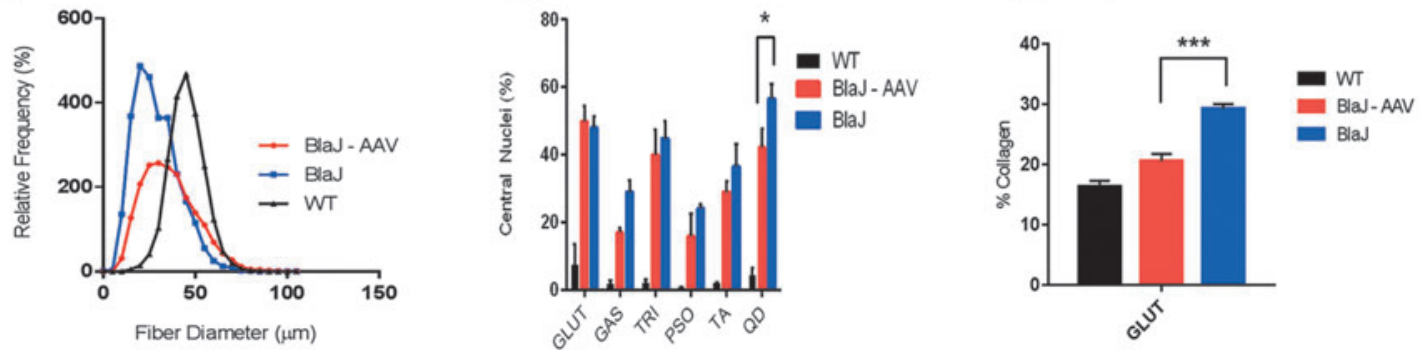

Figure 3. Long-term improvement in collagen deposition and immune staining with AAVrh74.MHCK7.DYSF.DV treatment. (A) At 15 months of age, H\&E staining demonstrated normalization of histology in treated psoas muscles (BlaJ-AAV). (B) Picosirius staining in the gluteus muscle demonstrated a reduction in collagen deposition. (C) Following long-term treatment in systemically treated mice, there was a trend toward normalization of fiber diameters and (D) reduced centrally located nuclei in the quadriceps muscle, as shown with H\&E staining. (E) Finally, there was a $9.0 \%$ reduction in collagen deposition using picosirius staining in the gluteus muscle. One-way ANOVAs were utilized with post hoc analysis to locate differences in the means. Error bars are represented as mean $\pm \operatorname{SEM}(p<0.05)$. 


\section{Long-term benefits from AAVrh74.DYSF.DV systemic gene transfer}

In order to evaluate the sustainment of benefit of intravenous gene transfer, additional cohorts of BlaJ mice were injected with $6 \times 10^{12} \mathrm{vg}$ of AAVrh74.DYSF.DV via the tail vein at 8 weeks of age $(n=8)$ and evaluated at 15 months post injection for histopathology (Fig. 3A) and fibrosis (Fig. 3B). In the gluteus muscle, fiber diameters were normalized (Fig. 3C), and reductions in central nuclei were noted to variable degrees, with reduction in quadriceps being significant (Fig. 3D and Supplementary Fig. S1). Collagen deposition was reduced to WT levels in the gluteus muscle
(Fig. 3D). Additionally, widespread transgene expression was detected at 15 months of age (Fig. 4A$\mathrm{C}$ ), and centrally located nuclei were only detected in the dysferlin null fibers (Fig. 4D). Less than $0.5 \%$ of dysferlin-positive fibers had central nuclei, demonstrating that the transgene derived dysferlin confers almost complete protection from degeneration. The presence of full-length dysferlin in treated muscles at 15 months of age was further confirmed by Western blot analysis (tibialis anterior and gastrocnemius; Fig. 4E).

As an outcome measure, in vivo MRI and MRS were used to evaluate gluteus and psoas muscles (MRS data not collected on the psoas due to inad-
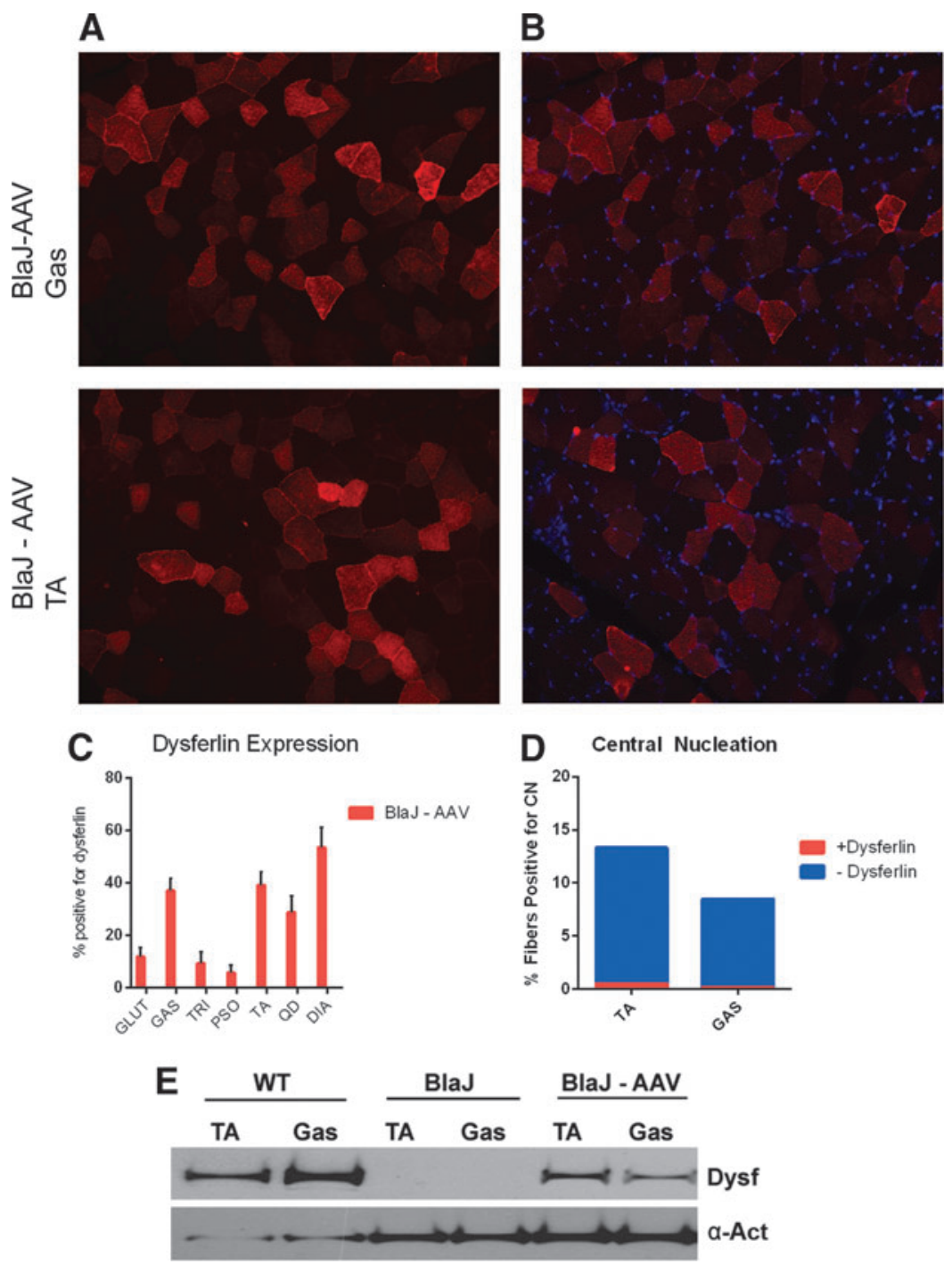

Figure 4. Long-term expression and normalization of centrally located nuclei in AAVrh74.MHCK7.DYSF.DV-treated mice. (A) Robust dysferlin expression was seen following systemic delivery $\left(6 \times 10^{12}\right.$ dose) using anti-dysferlin immune staining with an N-terminal antibody. Gastrocnemius (GAS) and TA muscles are shown for representation. (B) Sections were co-stained with DAPI to quantify dysferlin positive fibers co-localized with centrally located nuclei. (C) There was widespread dysferlin transgene expression at 15 months of age $>5 \%$ in all tissues, with the diaphragm expressing the highest at $53 \%$. (D) It is demonstrated that the majority of fibers with centrally located nuclei are absent of dysferlin expression $(<0.5 \%$ are positive for dysferlin and centrally located nuclei). (E) Fulllength dysferlin in treated muscles at 15 months of age was confirmed by Western blot analysis (TA and GAS) compared to wild-type and BlaJ-untreated muscle. 

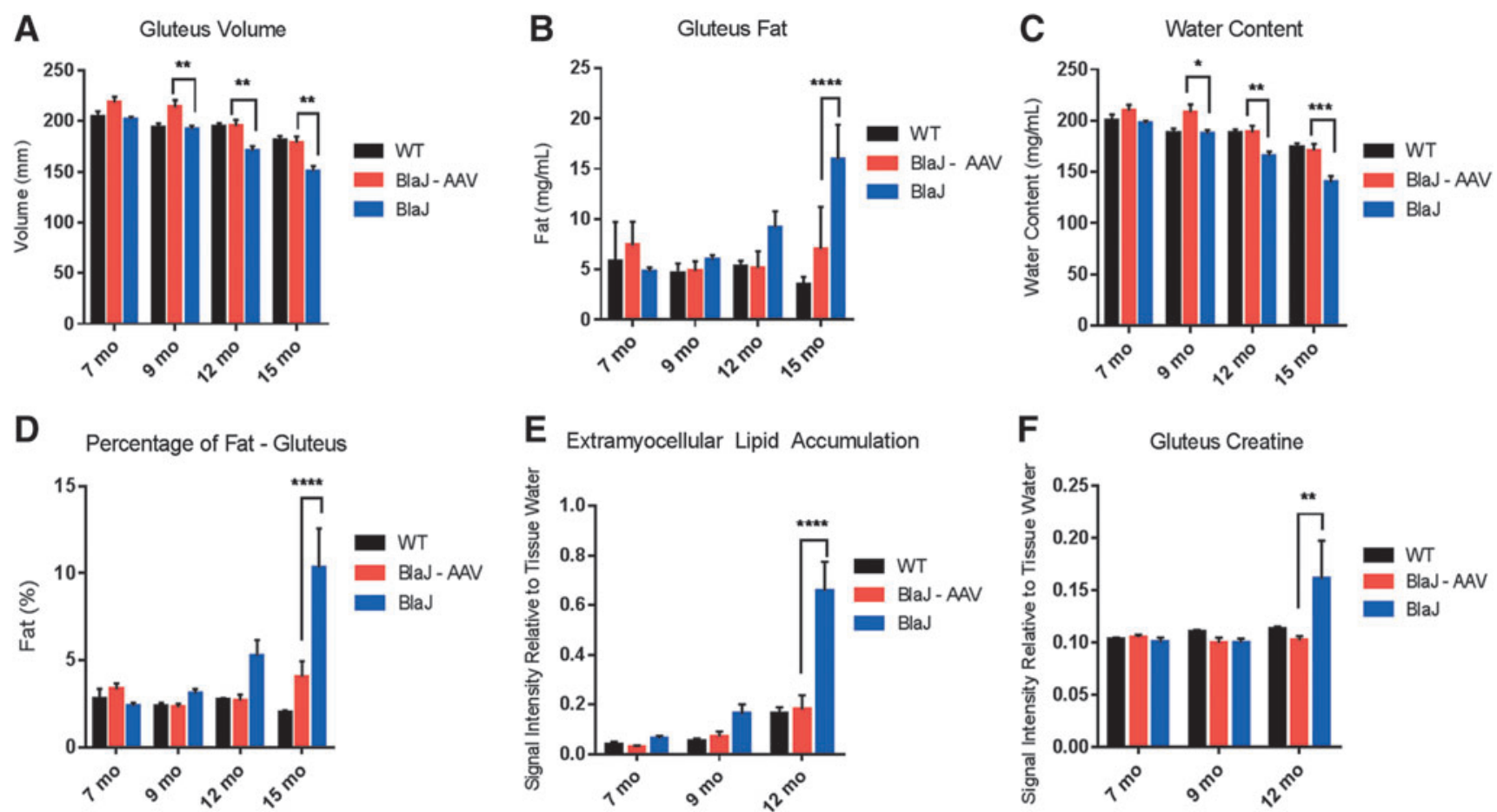

Figure 5. Long-term improvements using magnetic resonance imaging (MRI) in systemically treated mice with AAVrh74.MHCK7.DYSF.DV. (A) Animals underwent MRI after 7, 9, 12, and 15 months of age and demonstrated improvements in gluteus volume $(p<0.001)$, (B) decreased gluteus fat $(p<0.0001)$, (C) increased water content to wild-type levels $(p=0.223 ; p<0.01)$, and (D) decreased fat percentage significantly at the 15-month time points $(p<0.0001)$. (E) MR-spectroscopy was used to evaluate metabolite accumulation and decreased extramyocellular lipid accumulation was demonstrated in the gluteus muscle $(p<0.0001)$, as well as decreased creatine levels in the muscle to wild-type levels $(p=0.021)$ (F). Fifteen-month-old BLAJ animals were unable to undergo magnetic resonance spectroscopy evaluation due to excessive fat infiltration in the saline-treated cohort. Two-way ANOVAs with Tukey post hoc analysis were utilized to locate differences in the means. Error bars are represented as mean $\pm \operatorname{SEM}(p<0.05)$.

equate muscle size) and gluteus muscle volumes, fat content, extramyocellular lipid accumulation, and metabolite accumulation at $7,9,12$, and 15 months of age. Figure 5 demonstrates significantly increased gluteus volume (Fig. 5A), a reduction in fat content and percentage of fat (Fig. 5B-D), and a reduction of extramyocellular lipids and creatine accumulation (Fig. 5E-F) in the AAV-treated cohort, further supporting normalization of muscle content and functional improvement with longterm gene transfer of AAVrh74.DYSF.DV.

\section{AAVrh74.DYSF.DV systemic gene transfer in aged mice}

Clinically, dysferlinopathy is most commonly diagnosed after symptoms and loss of muscle function have begun. To evaluate whether AAVrh74 .DYSF.DV can potentially treat established disease, an aged cohort of BlaJ mice with established fibrosis and fiber loss was evaluated. AAVrh74 .DYSF.DV was systemically delivered through the tail vein of 6-month-old BlaJ mice, and animals were sacrificed 3 months post delivery. A statistically significant reduction of central nucleation
(Fig. 6A and Supplementary Fig. S1) and a slight decrease in fibrosis (Fig. 6B) were detected in the psoas of treated animals. Additionally, dysferlin expression resulted in functional improvement in membrane repair of FDB muscle fibers using a laser injury model (Fig. 6C). Therefore, AAVrh74 .DYSF.DV treatment demonstrates histologic and functional benefit to aged muscle with existing fibrosis.

\section{AAVrh74.DYSF.DV NHP systemic gene transfer}

To extend the preclinical findings further in mice toward a clinical paradigm, a rhesus macaque NHP model was treated systemically to confirm safety and efficacy for future clinical trials. Previously, the effect of $5 \times 10^{12} \mathrm{vg}$ total dose delivered by intramuscular injection to the left tibialis anterior of rhesus macaques of both AAV5.DYSF $(n=3)$ and AAVrh74.DYSF.DV $(n=2)$ was studied, and no aberrant responses or toxicity to either the capsid or the transgene were demonstrated. ${ }^{11}$ This study evaluated the effect of $2 \times 10^{14} \mathrm{vg} / \mathrm{kg}$ dose $\left(1 \times 10^{14}\right.$ $\mathrm{vg} / \mathrm{kg}$ of each vector) delivered intravenously 


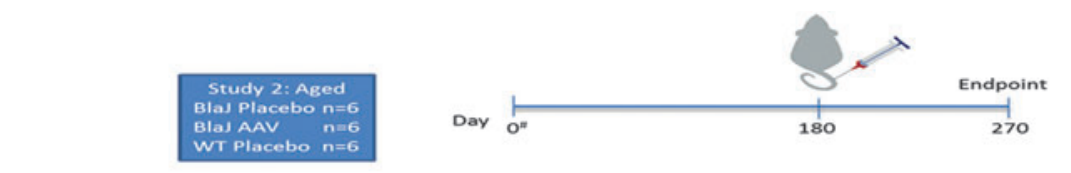

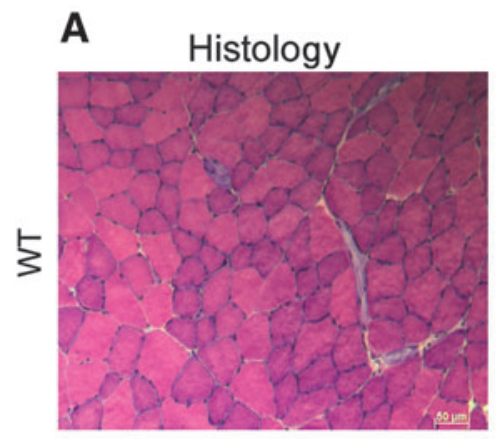

B Fibrosis
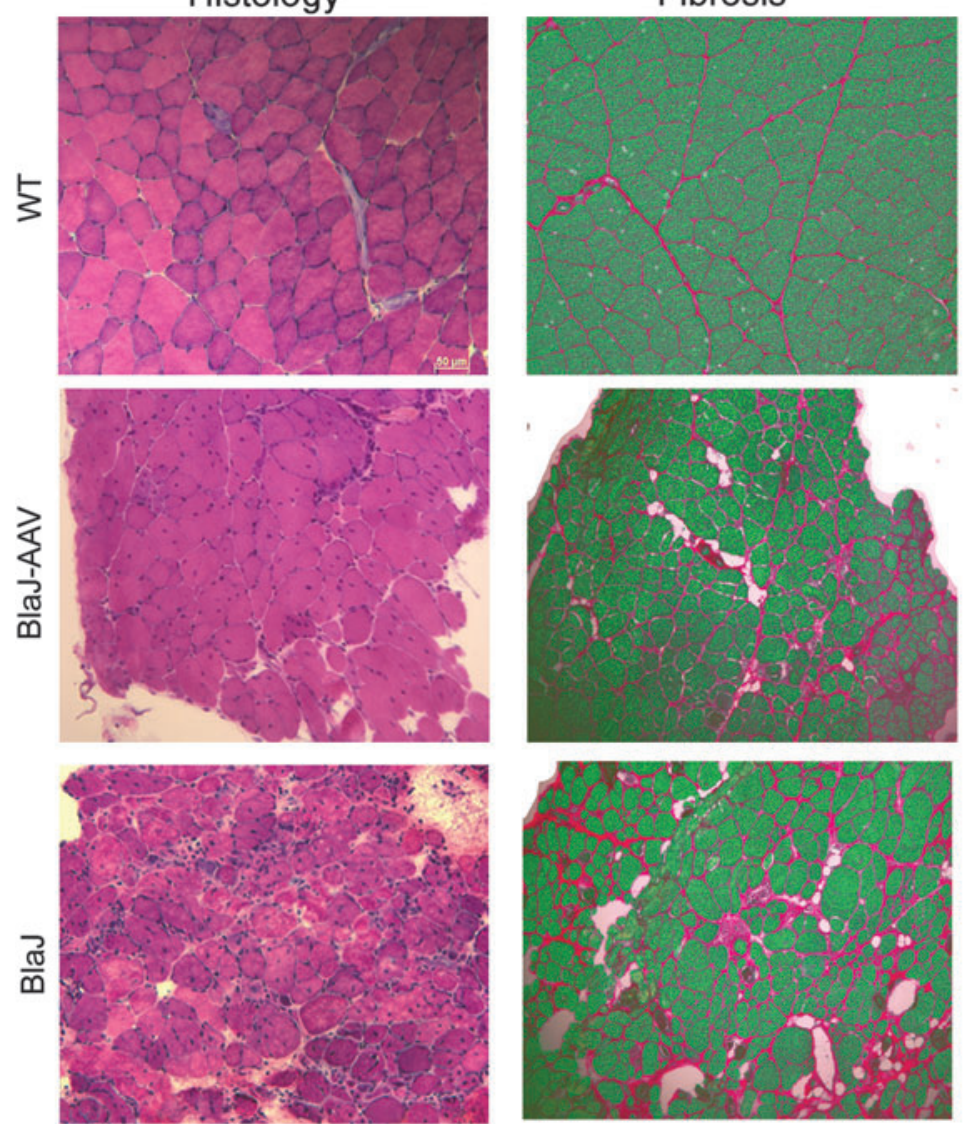

Centralized Nuclei

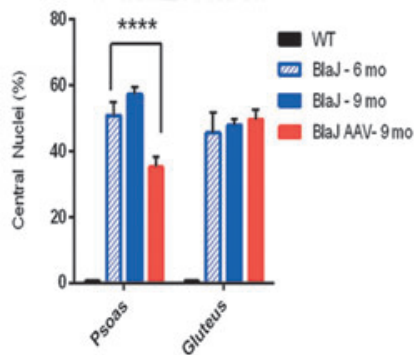

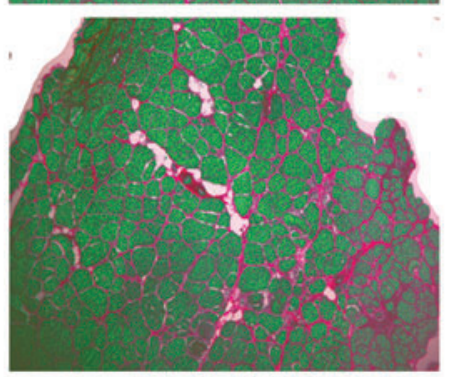

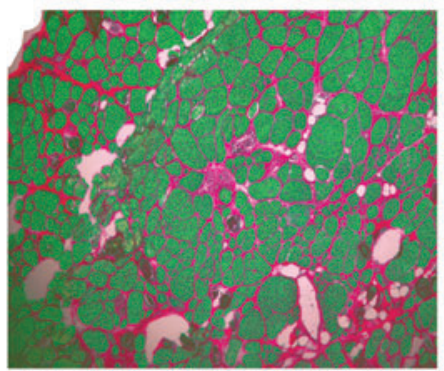

Collagen Quantification - Psoas

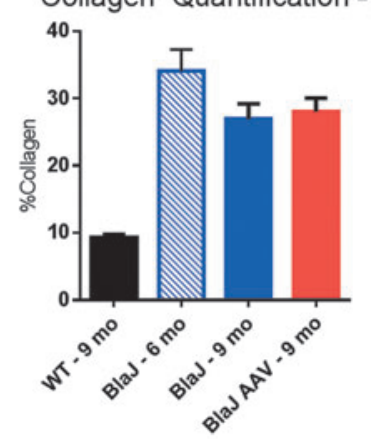

C Expression/Function
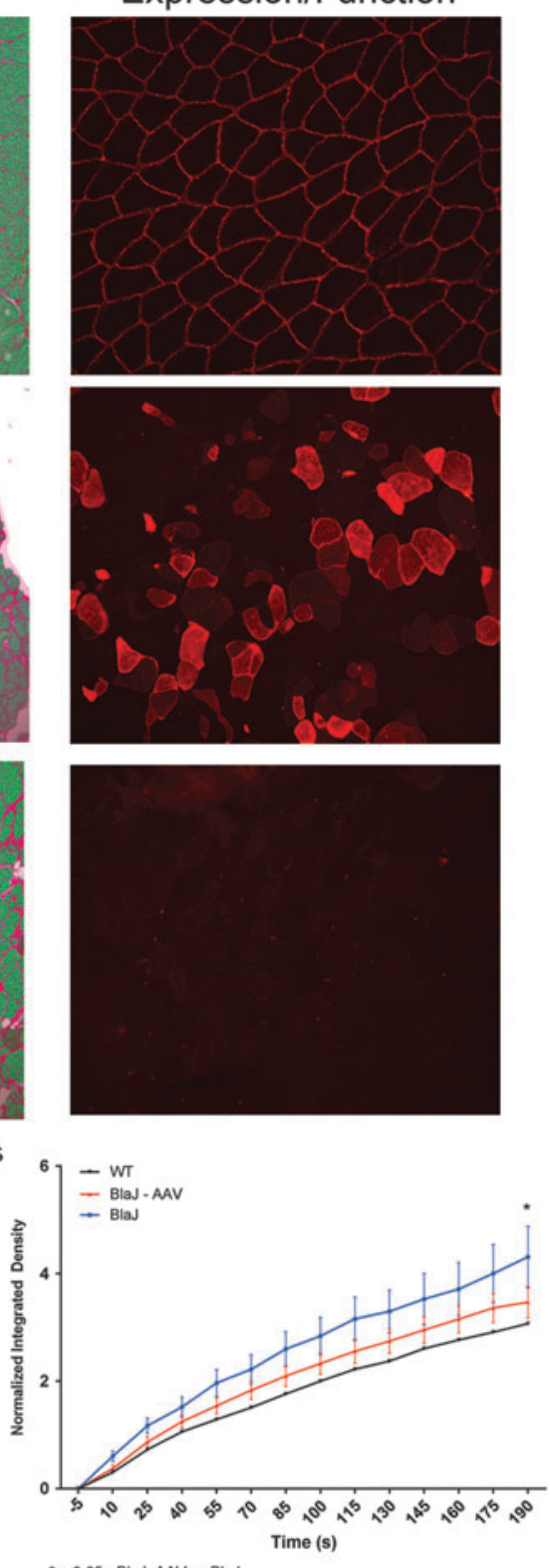

"p<0.05 - Blaj AAV vs BlaJ

Figure 6. Systemic expression and histological improvements in an aged cohort treated with AAVrh74.MHCK7.DYSF.DV. (A) Animals treated at 6 months of age and sacrificed at 9 months of age demonstrated reductions in centrally located nuclei in psoas muscle using H\&E staining. (B) There was slightly reduced collagen deposition between 6 and 9 months of age with treatment. (C) Dysferlin transgene expression was noted across all muscles following AAV treatment in this aged cohort, which led to significant improvement in membrane repair capacity in flexor digitorum brevis muscles $(p<0.05$ at $190 \mathrm{~s})$.

through the cephalic vein of a rhesus macaque. This dose was proportional (based on animal weight) to the systemic dose given to mice. Baseline chemistries were collected, and immunologic studies were performed, including interferon-gamma ELISpot analysis to measure T-cell responses to AAVrh74 capsid and dysferlin and anti-AAV antibody titers (ELISA) on enrolled animals. These studies were repeated every 2 weeks for the duration of the study. Three months following treatment, the animal was euthanized to obtain a full tissue necropsy. Tissues were used for gene expression 


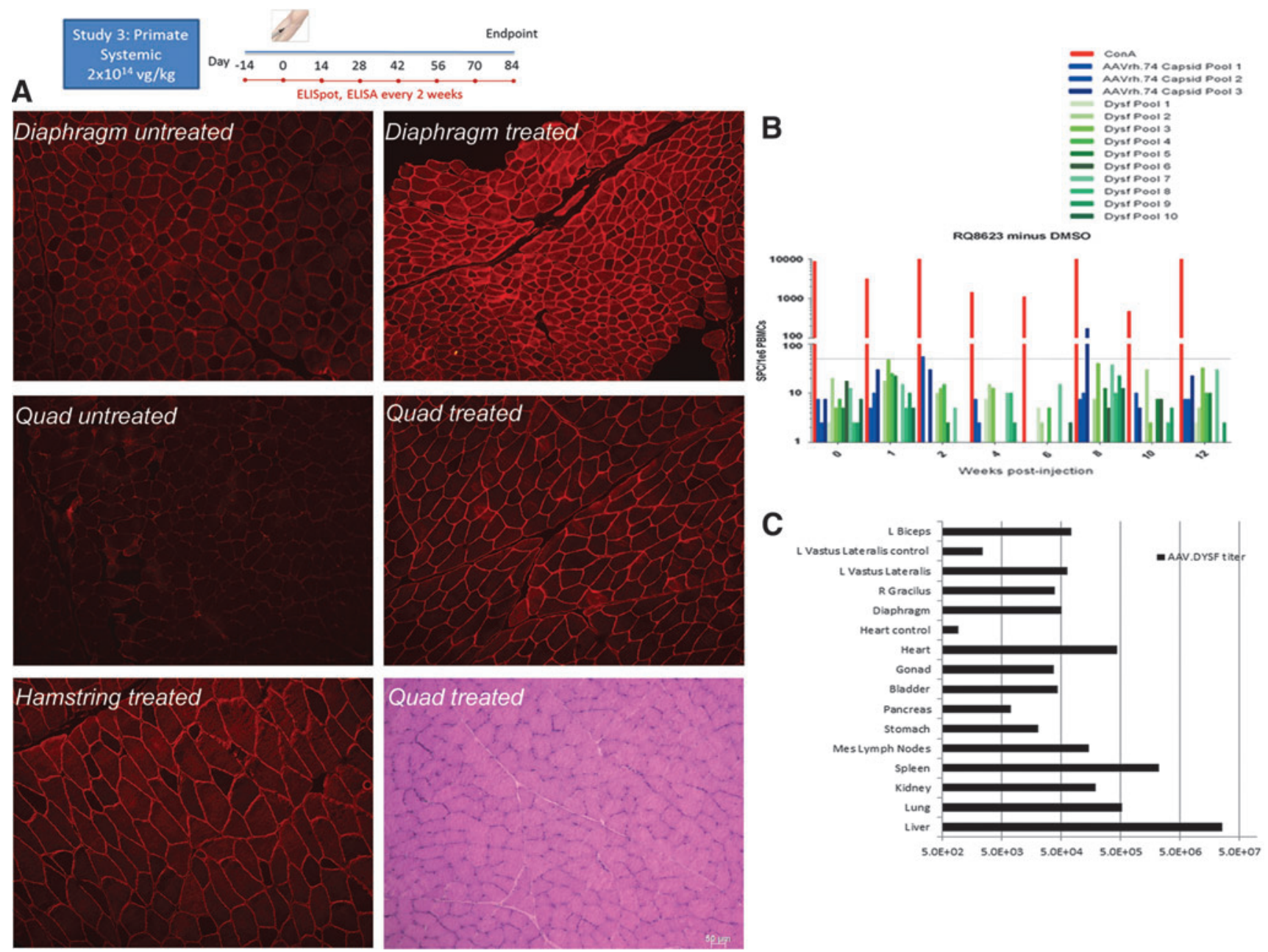

Figure 7. Systemic delivery in rhesus macaque with AAVrh74.MHCK7.DYSF.DV. (A) Anti-dysferlin immunofluorescence staining in untreated naïve rhesus macaque diaphragm and quadriceps muscles (left pane/ and systemically treated diaphragm, quadriceps, and hamstring demonstrates robust dysferlin expression. (B) Enzyme-linked immunosorbent spot assay analysis of T-cell response to dysferlin and AAV peptide pools demonstrates no adverse T-cell response in the presence of $(\mathbf{C})$ widespread vector genome $(\mathrm{vg} / \mu \mathrm{g}$ of genomic DNA) biodistribution quantified using quantitative polymerase chain reaction (qPCR). Vastus lateralis control and heart control in qPCR biodistribution refers to an uninjected male rhesus macaque.

(Fig. 7A) studies, including histopathology and biodistribution studies (Fig. 7C) on vital organs. Immunologic assays did not show any aberrant responses to the capsid or transgene by ELISpot or ELISA (Fig. 7B and Supplementary Table S1). In addition, full $\mathrm{CBC}$ and chemistry panels showed no abnormal values in the macaque (Supplementary Table S2). Systemic gene transfer in the NHP thereby established safety and efficacy and validated moving forward to clinical trial with AAVrh74 .DYSF.DV gene transfer.

\section{DISCUSSION}

Previously, successful dysferlin transgene expression and functional improvement in dysferlin-null mouse models were documented using intramuscular delivery and isolated limb perfusion delivery of AAVrh74.DYSF.DV. ${ }^{11}$ Intramuscular delivery to rhesus macaques demonstrated no toxicity and established proof of principle for movement toward the clinic, and a systemic delivery approach with the potential for robust clinical benefit was further pursued. The current study utilized systemic delivery of AAVrh74.DYSF.DV in young and aged mouse models and the rhesus macaque. This study demonstrates that systemic delivery using AAV-mediated gene delivery results in long-term, widespread transgene expression and functional recovery in both dysferlin-null mouse models and in the rhesus macaque. Treatment with AAVrh74 .DYSF.DV at 4 weeks of age demonstrated longterm transgene expression at 6 months of age out to 15 months of age. Furthermore, there were improvements in fiber diameters, centrally located nuclei, and collagen deposition, which contributed 
to stabilization of the muscle environment. As the disease progresses, the lipid content in the muscle typically increases, and the volume of infiltrates vary based on the muscle. Understanding this information is important in assessing improvements post gene therapy. Histologic improvements were corroborated with functional improvements using MRI/MRS measurements, in which reduced fat infiltration, retained lean muscle volumes, and increased water content were observed to WT levels in treated mice aged 15 months.

It was found that the timing of treatment administration and duration of treatment impact the degree of efficacy. However, sustained expression with histologic and functional benefit was achieved, irrespective of the treatment paradigm. This conclusion is pivotal for predicting the longterm success of systemic AAVrh74.DYSF.DV as a viable treatment for dysferlinopathy patients. The most striking results were realized with young animals treated prior to disease onset, where dysferlin expression persisted for 2 years with no reduction. Moreover, the development of centrally located nuclei, which indicates cycles of degeneration and regeneration, was completely arrested. These findings implore the establishment of newborn/early screening to identify dysferlinopathies during early childhood. This study demonstrates strong evidence that systematic treatment at a young age prior to disease onset has the potential to prevent disease. The results achieved in an aged cohort were equally intriguing. One of the big questions that is asked universally is whether gene replacement therapy has the potential to help muscular dystrophy patients with advanced disease. When mice were injected at 6 months of age with existing fibrosis and fiber loss, functional benefit was still achieved, evidenced by improvement in membrane repair. Reduction in centrally located nuclei and levels of fibrosis were also detected, along with efficient gene expression. Thus, there is a strong rationale that there is the potential for AAVrh74.DYSF.DV delivery to provide clinical benefit, regardless of disease status.
This study has shown that systemic AAVrh74.DYSF.DV treatment in macaque skeletal muscle can stimulate the overexpression of dysferlin with no apparent toxicity or systemic immune rejection, further validating the foundation of preclinical safety. Potential immune responses were carefully monitored through both serum ELISAs and PBMC ELISpot assays, and biodistribution was evaluated for both overlap vectors in all tissues and organs. The lack of immune response shown in the primate is therefore encouraging. Additionally, due to the lack of immune response and transgene overexpression in the rhesus macaque, the dose level utilized will be further translated into the clinic.

In conclusion, systemic delivery of the dual vector approach for dysferlinopathies provides a very promising therapeutic strategy for both younger and older subjects. The results in this study are encouraging in that they establish efficacy of safety and absence of toxicity, as well as improvements histologically and functionally with systemic delivery. Furthermore, the long-term transgene expression and functional improvements are promising as this treatment is moved toward the clinic.

\section{ACKNOWLEDGMENTS}

We thank the Nationwide Children's Viral Vector Core for Vector Production and Dr. Stephen Hauschka for his gift of the MHCK7 promoter. We would also like to thank Terri Shaffer, MLAS, RLATG, for performing intravenous tail-vein injections. This study was funded by the Jain Foundation and the Research Institute at Nationwide Children's Hospital to L.R.R.K.

\section{AUTHOR DISCLOSURE}

Dr. Rodino-Klapac is the inventor of the AAV .dysferlin dual vector technology. This technology has been licensed exclusively to Myonexus Therapeutics, Inc. Dr. Rodino-Klapac is a co-founder and Chief Scientific Officer for Myonexus Therapeutics, Inc. No competing financial interests exist for the remaining authors.

\section{REFERENCES}

1. Bansal D, Miyake K, Vogel SS, et al. Defective membrane repair in dysferlin-deficient muscular dystrophy. Nature 2003;423:168-172.

2. Moore SA, Shilling CJ, Westra $S$, et al. Limb-girdle muscular dystrophy in the United States. J Neuropathol Exp Neurol 2006;65:9951003
3. Rosales XQ, Gastier-Foster JM, Lewis S, et al. Novel diagnostic features of dysferlinopathies. Muscle Nerve 2010;42:14-21.

4. Rosales XQ, Moser SJ, Tran T, et al. Cardiovascular magnetic resonance of cardiomyopathy in limb girdle muscular dystrophy 2B and 2l. J Cardiovasc Magn Reson 2011;13:39.
5. Emmerling VV, Fischer $S$, Stiefel $F$, et al. Temperature-sensitive miR-483 is a conserved regulator of recombinant protein and viral vector production in mammalian cells. Biotechnol Bioeng 2016;113:830-841.

6. Aoki M, Liu J, Richard I, et al. Genomic organization of the dysferlin gene and novel mutations 
in Miyoshi myopathy. Neurology 2001;57:271278.

7. Liu J, Aoki M, Illa I, et al. Dysferlin, a novel skeletal muscle gene, is mutated in Miyoshi myopathy and limb girdle muscular dystrophy. Nat Genet 1998;20:31-36.

8. Liu J, Wu C, Bossie K, et al. Generation of a 3-Mb PAC contig spanning the Miyoshi myopathy/limbgirdle muscular dystrophy (MM/LGMD2B) locus on chromosome 2p13. Genomics 1998;49:23-29.

9. Grose WE, Clark KR, Griffin D, et al. Homologous recombination mediates functional recovery of dysferlin deficiency following AAV5 gene transfer. PLoS One 2012;7:e39233.

10. Lennon NJ, Kho A, Bacskai BJ, et al. Dysferlin interacts with annexins $A 1$ and $A 2$ and mediates sarcolemmal wound-healing. J Biol Chem 2003; 278:50466-50473.

11. Sondergaard PC, Griffin D, Pozsgai E, et al. AAV.dysferlin overlap vectors restore function in dysferlinopathy animal models. Ann Clin Transl Neurol 2015;2:256-270.

12. Kerr J, Ward C, Bloch R. Dysferlin at transverse tubules regulates $\mathrm{Ca}^{2+}$ homeostasis in skeletal muscle. Front Physiol 2014;5.

13. Lek A, Evesson F, Sutton B, et al. Ferlins: regulators of vesicle fusion for auditory neurotransmission, receptor trafficking and membrane repair. Traffic 2012;13:185-194.

14. Oulhen N, Onorato T, Ramos I, et al. Dysferlin is essential for endocytosis in the sea star oocyte. Dev Biol 2014;388:94-102.

15. Chiu YH, Hornsey MA, Klinge L, et al. Attenuated muscle regeneration is a key factor in dysferlindeficient muscular dystrophy. Hum Mol Genet 2009; 18:1976-1989.

16. de Morree A, Flix B, Bagaric I, et al. Dysferlin regulates cell adhesion in human monocytes. $J$ Biol Chem 2013:288:14147-14157.

17. Mariano A, Henning A, Han R. Dysferlin-deficient muscular dystrophy and innate immune activation. FEBS J 2013;280:4165-4176.

18. Millay DP, Maillet M, Roche JA, et al. Genetic manipulation of dysferlin expression in skeletal muscle: novel insights into muscular dystrophy. Am J Pathol 2009:175:1817-1823.

19. Lostal W, Bartoli M, Roudaut C, et al. Lack of correlation between outcomes of membrane repair assay and correction of dystrophic changes in experimental therapeutic strategy in dysferlinopathy. PLoS One 2012;7:e38036.

20. Walter MC, Reilich P, Thiele S, et al. Treatment of dysferlinopathy with deflazacort: a double-blind, placebo-controlled clinical trial. Orphanet J Rare Dis $2013 ; 8: 26$

21. Gallardo E, Rojas-Garcia R, de Luna $N$, et al. Inflammation in dysferlin myopathy: immunohistochemical characterization of 13 patients. Neurology 2001;57:2136-2138.
22. Fanin $\mathrm{M}$, Angelini $\mathrm{C}$. Muscle pathology in dysferlin deficiency. Neuropathol Appl Neurobiol 2002;28: $461-470$.

23. Barthelemy F, Wein N, Krahn M, et al. Translational research and therapeutic perspectives in dysferlinopathies. Mol Med 2011;17:875-882.

24. He B, Tang RH, Weisleder N, et al. Enhancing muscle membrane repair by gene delivery of MG53 ameliorates muscular dystrophy and heart failure in delta-Sarcoglycan-deficient hamsters. Mol Ther 2012;20:727-735.

25. Krahn $M$, Wein N, Bartoli $M$, et al. A naturally occurring human minidysferlin protein repairs sarcolemmal lesions in a mouse model of dysferlinopathy. Sci Transl Med 2010;2:50ra69.

26. Lostal W, Bartoli M, Bourg N, et al. Efficient recovery of dysferlin deficiency by dual adenoassociated vector-mediated gene transfer. Hum Mol Genet 2010;19:1897-1907.

27. Hofhuis J, Bersch K, Bussenschutt R, et al. Dysferlin mediates membrane tubulation and links $\mathrm{T}$ tubule biogenesis to muscular dystrophy. J Cell Sci 2017;130:841-852.

28. Chicoine LG, Rodino-Klapac LR, Shao G, et al. Vascular delivery of rAAVrh74.MCK.GALGT2 to the gastrocnemius muscle of the rhesus macaque stimulates the expression of dystrophin and laminin alpha2 surrogates. Mol Ther 2014;22:713-724.

29. Gao G, Vandenberghe LH, Wilson JM. New recombinant serotypes of AAV vectors. Curr Gene Ther 2005;5:285-297.

30. Heller KN, Montgomery CL, Janssen PM, et al. AAV-mediated overexpression of human alpha7 integrin leads to histological and functional improvement in dystrophic mice. Mol Ther 2013;21: 520-525.

31. Sahenk Z, Galloway G, Clark KR, et al. AAV1.NT-3 gene therapy for Charcot-Marie-Tooth neuropathy. Mol Ther 2014;22:511-521.

32. Grieger JC, Soltys SM, Samulski RJ. Production of recombinant adeno-associated virus vectors using suspension HEK293 cells and continuous harvest of vector from the culture media for GMP FIX and FLT1 clinical vector. Mol Ther 2016;24:287-297.

33. Emmerling VV, Pegel A, Milian EG, et al. Rational plasmid design and bioprocess optimization to enhance recombinant adeno-associated virus (AAV) productivity in mammalian cells. Biotechnol J 2016;11:290-297.

34. Qu W, Wang M, Wu Y, et al. Scalable downstream strategies for purification of recombinant adeno- associated virus vectors in light of the properties. Curr Pharm Biotechnol 2015;16:684-695.

35. Foust KD, Wang X, McGovern VL, et al. Rescue of the spinal muscular atrophy phenotype in a mouse model by early postnatal delivery of SMN. Nat Biotechnol 2010;28:271-274.

36. Wang D, Zhong L, Nahid MA, et al. The potential of adeno-associated viral vectors for gene delivery to muscle tissue. Expert Opin Drug Deliv 2014; 11:345-364.

37. Rodino-Klapac LR, Janssen PM, Montgomery CL, et al. A translational approach for limb vascular delivery of the micro-dystrophin gene without high volume or high pressure for treatment of Duchenne muscular dystrophy. J Transl Med 2007:5:45

38. Pozsgai ER, Griffin DA, Heller KN, et al. Systemic AAV-mediated beta-sarcoglycan delivery targeting cardiac and skeletal muscle ameliorates histological and functional deficits in LGMD2E mice. Mol Ther 2017;25:855-869.

39. Clark KR, Liu X, McGrath JP, et al. Highly purified recombinant adeno-associated virus vectors are biologically active and free of detectable helper and wild-type viruses. Hum Gene Ther 1999;10: 1031-1039

40. Ghosh A, Yue Y, Long C, et al. Efficient whole-body transduction with trans-splicing adeno-associated viral vectors. Mol Ther 2007:15:750-755.

41. Emmerling VV, Fischer S, Kleemann M, et al. miR483 is a self-regulating microRNA and can activate its own expression via USF1 in HeLa cells. Int J Biochem Cell Biol 2016;80:81-86.

42. Toromanoff A, Cherel Y, Guilbaud M, et al. Safety and efficacy of regional intravenous (RI) versus intramuscular (IM) delivery of rAAV1 and rAAV8 to nonhuman primate skeletal muscle. Mol Ther 2008 ; 16:1291-1299.

43. Rodino-Klapac LR, Montgomery CL, Bremer WG, et al. Persistent expression of FLAG-tagged micro dystrophin in nonhuman primates following intramuscular and vascular delivery. Mol Ther 2010; 18:109-117.

44. Schnepp BC, Jensen RL, Chen CL, et al. Characterization of adeno-associated virus genomes isolated from human tissues. J Virol 2005;79: 14793-14803.

45. Labikova J, Vcelakova J, Ulmannova T, et al. The cytokine production of peripheral blood mononuclear cells reflects the autoantibody profile of patients suffering from type 1 diabetes. Cytokine 2014:69:189-195

46. Roche JA, Ru LW, O'Neill AM, et al. Unmasking potential intracellular roles for dysferlin through improved immunolabeling methods. J Histochem Cytochem 2011;59:964-975.

47. Vontzalidis A, Terzis G, Manta P. Increased dysferlin expression in Duchenne muscular dystrophy. Anal Quant Cytopathol Histpathol 2014;36:15-22.

48. Nagy N, Nonneman RJ, Llanga T, et al. Hip region muscular dystrophy and emergence of motor deficits in dysferlin-deficient Bla/J mice. Physiol Rep 2017;5.

Received for publication April 18, 2017; accepted after revision July 12, 2017.

Published online: July 13, 2017. 